\title{
Medial forebrain bundle stimulation during learning and subsequent retention disruption
}

\author{
ELAINE L. BRESNAHAN \\ Essex Community College, Baltimore, Maryland 21237 \\ and \\ ARYEH ROUTTENBERG \\ Northwestern University, Evanston, Illinois 60201
}

\begin{abstract}
One hundred and fifteen male albino rats were used to evaluate 24-h retention of a passive avoidance task following low-level brain stimulation applied during original learning but not during retention. Since the amygdala, substantia nigra, and prefrontal cortex send their afferents through lateral hypothalamus-medial forebrain bundle (MFB), and they have been previously implicated in brain stimulation disruption of memory, the anterior, middle, and posterior portions of the MFB were stimulated. Statistically significant retention deficits relative to operated controls were observed. No impairment in original learning was detected between stimulated animals and operated controls. The disruptive effects of MFB stimulation on retention may be related to the disorganizing influence of the electrical stimulation on amygdaloid, nigro-neostriatal, and frontal cortical fiber systems normally involved in processes leading to retention of this passive avoidance response.
\end{abstract}

Using unilateral low-level electrical stimulation, it is possible to localize retention disruptive effects to particular brain nuclei within a structure (Kesner \& Wilburn, 1974). In a study of ventral midbrain tegmentum, Routtenberg and Holzman (1973) demonstrated disruptive effects following stimulation in the substantia nigra, pars compacta, and similar involvement of the medial wall of the frontal cortex was demonstrated by Santos-Anderson and Routtenberg (1976).

The present authors have found that unilateral electrical stimulation of the medial amygdaloid nucleus resulted in retention disruption for a previously learned passive avoidance response (Bresnahan \& Routtenberg, 1972). The level of stimulation used in that experiment did not produce epileptiform activity either at the amygdaloid site of stimulation or in the hippocampus, nor did it sustain motivational consequences. Thus, electrical stimulation has been useful in pointing to particular cytoarchitectural regions within the substantia nigra, frontal cortex, and amygdala which play a role in retention performance.

Since specific nuclear groups within the three brain regions mentioned above have been implicated in retention performance deficits, it was worthwhile to

Elaine Bresnahan was supported by NIMH postdoctoral research fellowships. Support was also provided by the Alfred P. Sloan Foundation, and NIH Grants MH17255 and MF25281 to Aryeh Routtenberg. Reprint requests should be sent to Elaine Bresnahan, Psychology Department, Essex Community College, Baltimore, Maryland 21237. determine whether the pathways related to these structures also give rise to the same retention performance disruption. A focus of interest in regard to the amygdaloid, nigral, and frontal cortical connections was the interesting coincidence that each system contributes to, or passes near, the medial forebrain bundle (MFB). Reciprocal connections between the amygdala and hypothalamus have also been described by Cowan, Raisman, and Powell (1965), and it was suggested that the ventral amygdala pathway may be regarded as a rostral and lateral continuation of the MFB into the amygdala. With regard to the substantia nigra, it has been shown that the substantia nigra ascends through the lateral aspect of the MFB, intercalated both with this system and the most medially located fibers of the internal capsule (Moore, Bhatnagar, \& Heller, 1971). The medial frontal cortex sends descending projections that occupy a similar lateral position within the MFB (Leonard, 1969; Routtenberg, 1970). Since the substantia nigra, frontal cortex, and the amygdala have an intimate association with the MFB, it would be expected that stimulation of the MFB during learning would produce disruptive effects on retention performance as has been observed during stimulation of the nuclear groups that sent projections through the bundle. The present experiment confirms this expectation.

\section{METHOD}

This experiment was completed in two phases. ${ }^{1}$ For Phase 1 , electrodes were directed toward posterior locations of the MFB 
whereas, for Phase 2, the electrodes were directed toward more anterior locations of the MFB.

Phase 1
Subjects
Thirty-seven male Holtzman albino rats, 60 to 90 days of age
and ranging between 240 and $300 \mathrm{~g}$ at the time of surgery, were
unilaterally implanted with bipolar electrodes. Twenty-nine of
these surgically implanted animals were stimulated during passive
avoidance learning and eight were nonstimulated but surgically
implanted controls. Twenty unoperated animals were used as an
additional control group.

\section{Apparatus.}

The passive avoidance chamber, previously described by Bresnahan and Routtenberg (1972), was a black wooden box with a clear Plexiglas lid that had a small platform extending across one end of the box. A Grason-Stadler scrambled shock source (E6070B) provided .5-mA shock to a stainless steel rod grid floor. Brain stimulation and footshock sources were floating with respect to ground, using isolation transformers, and the two forms of stimulation were never on at the same time. Thus, possible interaction of brain stimulation and footshock was excluded. Brain-stimulation current level $(10 \mu \mathrm{A}$ peak to peak, $60-\mathrm{Hz}$ sine wave) was monitored on a Tektronix 564 oscilloscope. A commutator-type swivel assembly prevented the cable from twisting while the animal was turning.

\section{Procedure}

Surgery. Following administration of pentobarbital anesthesia $(40 \mathrm{mg} / \mathrm{kg})$ each animal was implanted with a single bipolar electrode made with $254-\mu$-diam enamel-insulated nichrome wire. An additional coat of Epoxylite insulation was applied prior to cutting the electrode wires to the predetermined length. Implantation in all cases was perpendicular to the skull.

Coordinates for implantation were obtained by placing electrodes in pilot animals adjusting coordinates until the electrode tip was observed in the desired posterior MFB location. The König and Klippel (1963) atlas was used to guide stereotaxic coordinates. These coordinates for electrode implantation in the posterior MFB were varied from 2.0 to $4.0 \mathrm{~mm}$ posterior to bregma, 1.5 to $2.5 \mathrm{~mm}$ lateral to midline, and 8.2 to $8.5 \mathrm{~mm}$ below the top surface of the skull. The intended variation in electrode placement allowed sampling along the rostral caudal dimension as well as within the medial-lateral dimension of the posterior portion of the MFB. Following surgery, all animals were injected with 100,000 $\mathrm{U}$ of procaine penicillin and returned to their home cages. A 5- to 7-day recovery period was allowed before the beginning of the behavioral experiment.

Learning and retention. Following the recovery period, each animal was subjected to passive avoidance training. Before placement in the testing situation, the electrode clip was attached and brain stimulation was adjusted to $10 \mu \mathrm{A}$ peak-to-peak current level. The animal was then placed on the platform and brain stimulation continued until the first descent was made. At this time, brain stimulation was discontinued and current to the grid floor began. When the animal returned to the platform to escape footshock, brain stimulation began again and continued until another descent was made or until the learning criterion was reached. Operated controls had this electrode clip attached but no brain stimulation was applied.

The learning criterion was achieved when the subject remained on the platform for 2 min without a descent. It was previously observed that in this passive avoidance step-down task, subjects differ in the number of descents and total time to achieve criterion (Bresnahan \& Routtenberg, 1972). Thus, the task for most animals is not a one trial task, but rather a multiple trial passive avoidance learning task. Since the number of descents varied, a criterion of 2 min on the platform without a descent was used in order to equate original learning.
After attaining the learning criterion, the animal was removed from the apparatus and placed in the home cage for $24 \mathrm{~h}$. The animal was then returned to the passive avoidance apparatus and placed on the platform for a 3-min retention test. Latency of first descent during this test was the measure used for data analysis. Retention of the passive avoidance response was demonstrated by remaining on the platform for $180 \mathrm{sec}$. A latency of less than $180 \mathrm{sec}$ was considered to indicate a deficit in performance during retention. The phrases "retention deficit" and "retention disruption" are used throughout the paper to refer to such an occurrence. While a retention test of any length imposes a ceiling effect on the data analysis, an unlimited retention test is not practical, as some control animals may remain on the platform for a relatively long duration.

Histology. After completion of testing, the subjects were injected with an overdose of sodium pentobarbital and perfused with physiological saline and 10\% Formalin. Dissected brains were fixed in Formalin for 5 to 7 days and then immersed in $20 \%$ ethanol for an additional 2 days. Frozen $30-\mu$ sections were taken and stained alternately by the method of Weil (1928) and the thionin Nissl stain to facilitate identification of the deepest point of electrode penetration.

\section{Phase 2}

In this second phase of the experiment, more anterior MFB locations were sampled for retention disruptive effects of stimulation. In addition, it was deemed advisable to determine the possible motivational consequences (rewarding and/or aversive) of the stimulation. This was done by testing for approach and withdrawal effects of brain stimulation in a tilt cage (Bresnahan \& Routtenberg, 1972; Valenstein \& Myers, 1964).

\section{Subjects}

Fifty-eight male Holtzman rats, 60 to 90 days of age, were used as subjects. Of the 47 animals with implanted electrodes, 26 served as stimulated animals and 21 served as implanted controls. The remaining 11 animals were unoperated controls.

\section{Apparatus}

The passive avoidance apparatus was similar to that described before except that (a) the box was made of opaque black plastic instead of wood, and (b) footshock of $1 \mathrm{~mA}$ was provided by a Foringer Model 1154 scrambled shock source. Although footshock current level was higher in this second phase, response to the aversive stimulus in the two experimental situations was judged to be similar.

\section{Procedure}

Surgery. Surgical procedures were the same as those in Phase 1 except that coordinates ranged from 0 to $1.3 \mathrm{~mm}$ posterior to bregma, 1.5 to $2.0 \mathrm{~mm}$ lateral to midline, and 7.9 to $8.2 \mathrm{~mm}$ below the top surface of the skull.

Learning and retention. Learning and retention procedures were the same as those previously described.

Rewarding and aversive effects of brain stimulation. Approach and withdrawal effects of brain stimulation were evaluated in all animals in the tilt type cage. Five days after the 24-h retention test, the animals were tested individually in the tilt box for 10 min daily on 8 successive days. Continuous brain stimulation at the intensity level used during learning was alternated from one side of the tilt box to the other in 1 -min periods. The criterion used for reward or aversion was comparable to a previously used criterion (Bresnahan \& Routtenberg, 1972). That is, receiving less than $3.3 \mathrm{~min}$ of brain stimulation during any one 10-min test was defined as a aversive event, and receiving more than 6.6 min of stimulation was defined as a rewarding event.

Histology. Brains were dissected and fixed with Formalin solution as described in Phase 1. Frozen $30-\mu$ sections through the electrode track were photographed while wet and were later stained by the method of Weil (1928). 


\section{RESULTS}

\section{Phase 1}

\section{Electrode Placements}

The electrode placements for the 29 stimulated animals (11 in MFB and 18 non-MFB) and for the 8 implanted controls (5 in MFB and 3 non-MFB) are shown in Figure 1. Eight of the 11 MFB stimulated animals showed a retention test latency of $<180 \mathrm{sec}$. All 8 placements were in the dorsal or lateral portion of the MFB, whereas the remaining 3 MFB placements (no retention deficit) were in the dorsomedial and ventromedial portions of the MFB. Eighteen stimulated animals had electrode placements outside but adjacent to the MFB and only 2 of these 18 animals showed retention disruption. For one animal showing disruption, the electrode tip rested in the edge of the internal capsule adjacent to the MFB (Section 4,
Figure 1) and for the other animal, the electrode tip was located in the ventromedial hypothalamic nucleus (Section 6, Figure 1). No retention disruption occurred in the MFB implanted controls or in the non-MFB implanted controls.

\section{Learning}

Stimulation in the MFB had no effect on the two recorded learning measures as indicated by the Kruskal-Wallis analysis of variance. Table 1 shows the median latencies of first descent and median number of descents during learning for individual stimulated and nonstimulated groups.

\section{Retention}

The median 24-h retention latencies from stimulated and nonstimulated groups are shown in Table 1. A Kruskal-Wallis analysis of variance of the 24-h

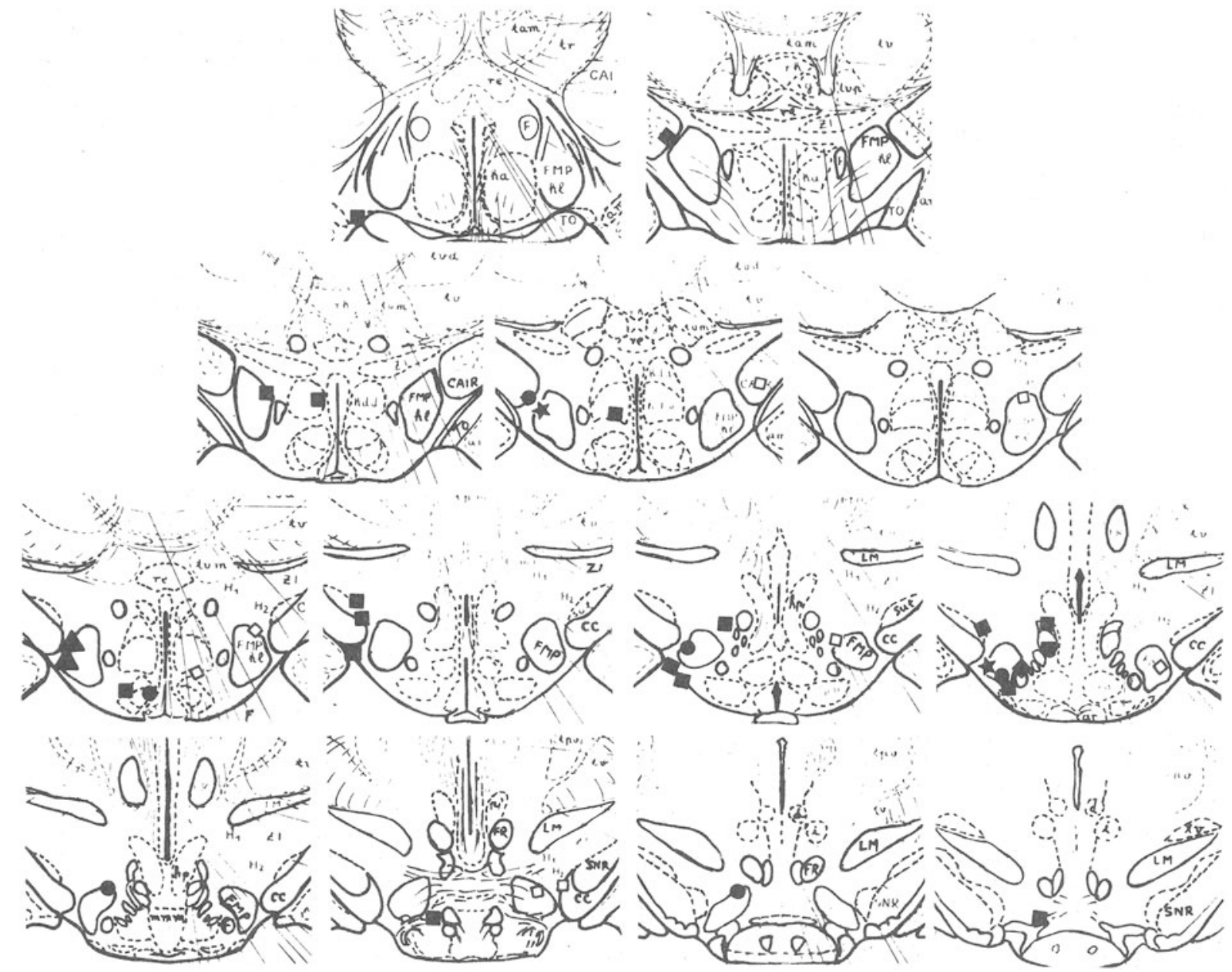

Figure 1. Electrode placements for stimulated animals in Phase 1 appear on the left and are indicated by closed symbols. Eleven placements are in the MFB and 18 are in adjacent areas. Electrode placements for 8 control animals (implanted but not stimulated) are included on the right side and are indicated by open symbols. Retention latencies are shown by the following: circles $=1-59$ sec; stars $=60-119 \mathrm{sec} ;$ triangles $=120-179 \mathrm{sec} ;$ and squares $=180 \mathrm{sec}$. 
Table 1

Effect of Brain Stimulation on Learning and 24-H Retention

\begin{tabular}{|c|c|c|c|c|c|c|c|c|}
\hline \multirow[b]{3}{*}{ Group } & & \multirow[b]{3}{*}{$\mathrm{n}$} & \multicolumn{4}{|c|}{ Learning } & \multirow{2}{*}{\multicolumn{2}{|c|}{$\begin{array}{c}\text { Retention } \\
\text { Latency First } \\
\text { Descent in Sec }\end{array}$}} \\
\hline & & & \multicolumn{2}{|c|}{$\begin{array}{c}\text { Latency First } \\
\text { Descent in Sec }\end{array}$} & \multicolumn{2}{|c|}{$\mathrm{n}$ of Descents } & & \\
\hline & & & Median & Range & Median & Range & Median & Range \\
\hline & & & & & Phase & & & \\
\hline Stimulated & $\begin{array}{l}\text { MFB } \\
\text { Non-MFB }\end{array}$ & $\begin{array}{l}11 \\
18\end{array}$ & $\begin{array}{l}3.2 \\
2.0\end{array}$ & $\begin{array}{l}1-20 \\
1-114\end{array}$ & $\begin{array}{l}2.2 \\
1.8\end{array}$ & $\begin{array}{l}1-5 \\
1-5\end{array}$ & $\begin{array}{r}98.0 \\
179.9\end{array}$ & $\begin{array}{r}1-180 \\
10-180\end{array}$ \\
\hline Implanted Controls & $\begin{array}{l}\text { MFB } \\
\text { Non-MFB }\end{array}$ & $\begin{array}{l}5 \\
3\end{array}$ & $\begin{array}{l}2.2 \\
5.0\end{array}$ & $\begin{array}{l}1-8 \\
1-11\end{array}$ & $\begin{array}{l}2.2 \\
2.2\end{array}$ & $\begin{array}{l}1-4 \\
2-3\end{array}$ & $\begin{array}{l}180.0 \\
180.0\end{array}$ & $\begin{array}{l}0 \\
0\end{array}$ \\
\hline Unoperated Controls & & 20 & 7.5 & $1-18$ & 1.9 & $1-5$ & 179.9 & $42-180$ \\
\hline Stimulated & $\begin{array}{l}\text { MFB-Rostral Level } \\
\text { MFB-1po Level* } \\
\text { MFB-1h Level* } \\
\text { Non-MFB }(n=9) * *\end{array}$ & $\begin{array}{l}4 \\
8 \\
5 \\
7\end{array}$ & $\begin{array}{l}1.2 \\
3.0 \\
1.3 \\
1.4\end{array}$ & $\begin{array}{ll}1- & 4 \\
1- & 7 \\
1- & 7 \\
1- & 6\end{array}$ & $\begin{array}{l}\text { Phase } \\
3.0 \\
3.2 \\
3.2 \\
3.7\end{array}$ & $\begin{array}{l}2-8 \\
2-9 \\
1-7 \\
1-9\end{array}$ & $\begin{array}{r}89.0 \\
21.0 \\
26.0 \\
179.8\end{array}$ & $\begin{array}{l}1-180 \\
1-70 \\
1-180 \\
4-180\end{array}$ \\
\hline Implanted Controls & $\begin{array}{l}\text { MFB-Rostral Level } \\
\text { MFB-1po Level } \\
\text { MFB-h Level } \\
\text { Non-MFB }(n=2) \dagger\end{array}$ & $\begin{array}{r}1 \\
6 \\
12\end{array}$ & $\begin{array}{l}1.0 \\
1.2 \\
3.5\end{array}$ & $\begin{array}{l}1-10 \\
1-32\end{array}$ & $\begin{array}{l}2.0 \\
3.0 \\
2.5\end{array}$ & $\begin{array}{l}2-7 \\
14\end{array}$ & $\begin{array}{r}15.0 \\
179.2 \\
179.7\end{array}$ & $\begin{array}{r}11-180 \\
1-180\end{array}$ \\
\hline Unoperated Controls & & 11 & 3.2 & $1-35$ & 2.6 & 14 & 180.0 & 0 \\
\hline
\end{tabular}

*Abbreviations from König and Klippel (1963): lpo = lateral preoptic nucleus; lh = lateral hypothalamic nucleus.

**Two animals in this group showed an aversive effect of brain stimulation and thus were not used in the data analysis.

fOmitted from the data analysis as $n$ is too small.

retention test data indicated significant groups differences $(p<.001)$. Individual comparisons, MannWhitney U tests, indicated that MFB stimulated animals had significantly lower retention test latencies than non-MFB stimulated animals $(\mathrm{p}<.05)$, implanted nonstimulated animals $(\mathrm{p}<.02)$, and unoperated controls $(p<.002)$. There were no significant differences among the control groups.

As an additional control specifically for electrode track lesioning effects, 16 stimulated animals implanted with fine wire electrodes (78.7- $\mu$ wire) and 8 nonstimulated implanted controls were observed during learning and retention. Similar results to those presented above were found for MFB stimulated and non-MFB stimulated animals. That is, MFB stimulation resulted in retention disruption, whereas nonMFB stimulation (adjacent areas) and implantation of the electrode only did not. It should be noted that with this finer wire, the electrode track is barely visible when viewed with a microprojector. Thus, since the behavioral results are similar in the two situations, lesioning effects from the regularly used electrodes are minimal.

\section{Electrode Placements}

\section{Phase 2}

Analysis of the histological material shown in Figures 2 and 3 indicated that 17 animals had electrodes located in the MFB, 4 rostral to the preoptic level, 8 at the lateral preoptic level, and 5 at the lateral hypothalamic level. Fourteen of these stimulated animals showed retention disruption. In addition, 9 stimulated animals had electrode placements in nonhypothalamic areas. Since 2 of these animals showed an aversive effect of brain stimulation, they were not used in the subsequent data analyses. These placements, which resulted in aversive effects, are marked with arrows in Figure 2, one occurring along diagonal tract fibers and one cutting through the anterior commissure resting in the edge of the stria terminalis.

As shown in Figures 2 and 3, 19 of the 21 implanted controls had electrode tips located in the MFB and 7 of the 19 showed retention disruption. Two of the 21 controls had placements located outside hypothalamic areas, one along the lateral cortico-habenular tract, and one along diagonal tract fibers (this animal showed retention disruption).

\section{Learning}

Table 1 also shows the learning data for 24 stimulated animals, 19 implanted controls, and 11 unoperated controls. Kruskal-Wallis analyses of variance on each of the two learning measures indicated no significant differences among groups.

\section{Retention}

A Kruskal-Wallis analysis of variance of the 24-h retention test data for MFB stimulated, MFB implanted controls, nonhypothalamic stimulated, and unoper-. ated control groups indicated significant differences 


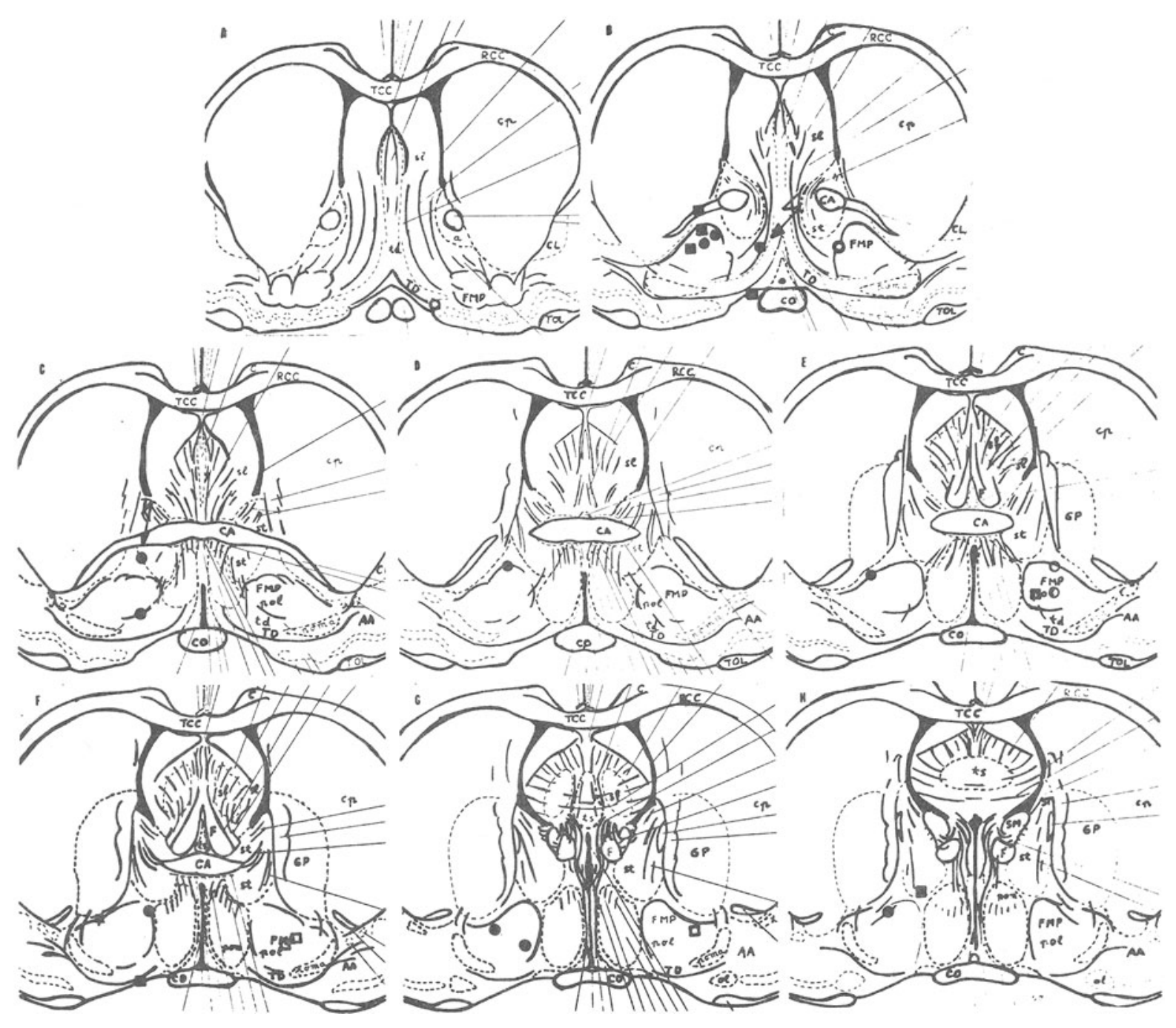

Figure 2. Electrode placements in Phase 2 for stimulated animals and implanted controls with MFB placements at the rostral and lateral preoptic levels. Retention latencies are indicated as described under Figure 1. Stimulated animals appear on the left and implanted controls on the right. Arrows indicate placements for two animals showing an aversive motivational property of the brain stimulation.

among groups $(\mathrm{p}<.001)$. Individual comparisons, two-tailed Mann-Whitney U tests, indicated that the MFB stimulated group differed from the MFB implanted controls $(p<.02)$, the nonhypothalamic stimulated animals $(\mathrm{p}<.02)$, and the unoperated controls $(p<.002)$. There were no significant differences among the MFB controls, the nonhypothalamic stimulated, or the unoperated controls. The median 24-h retention test latencies are shown on Table 1.

\section{Motivational Property of Brain Stimulation}

Evaluation of the motivational property of brain stimulation in the tilt box revealed no rewarding or aversive effects for MFB stimulated animals. However, two animals stimulated in nonhypothalamic areas showed an aversive effect of stimulation. Electrode placements for these two animals are marked by arrows in Figure 2.

\section{DISCUSSION}

This is the first report of retention disruption following stimulation of the medial forebrain bundle (MFB) only during original learning. Prior reports of MFB stimulation and of lesions leading to impairment in learning and performance of learned tasks are consistent with the present results (Briese \& J. Olds, 1964; Kent \& Grossman, 1973; M. E. Olds, \& J. Olds, 1961). As pointed out previously with respect to intracranial self-stimulation, the MFB contains several fiber pathways, which by themselves probably are 


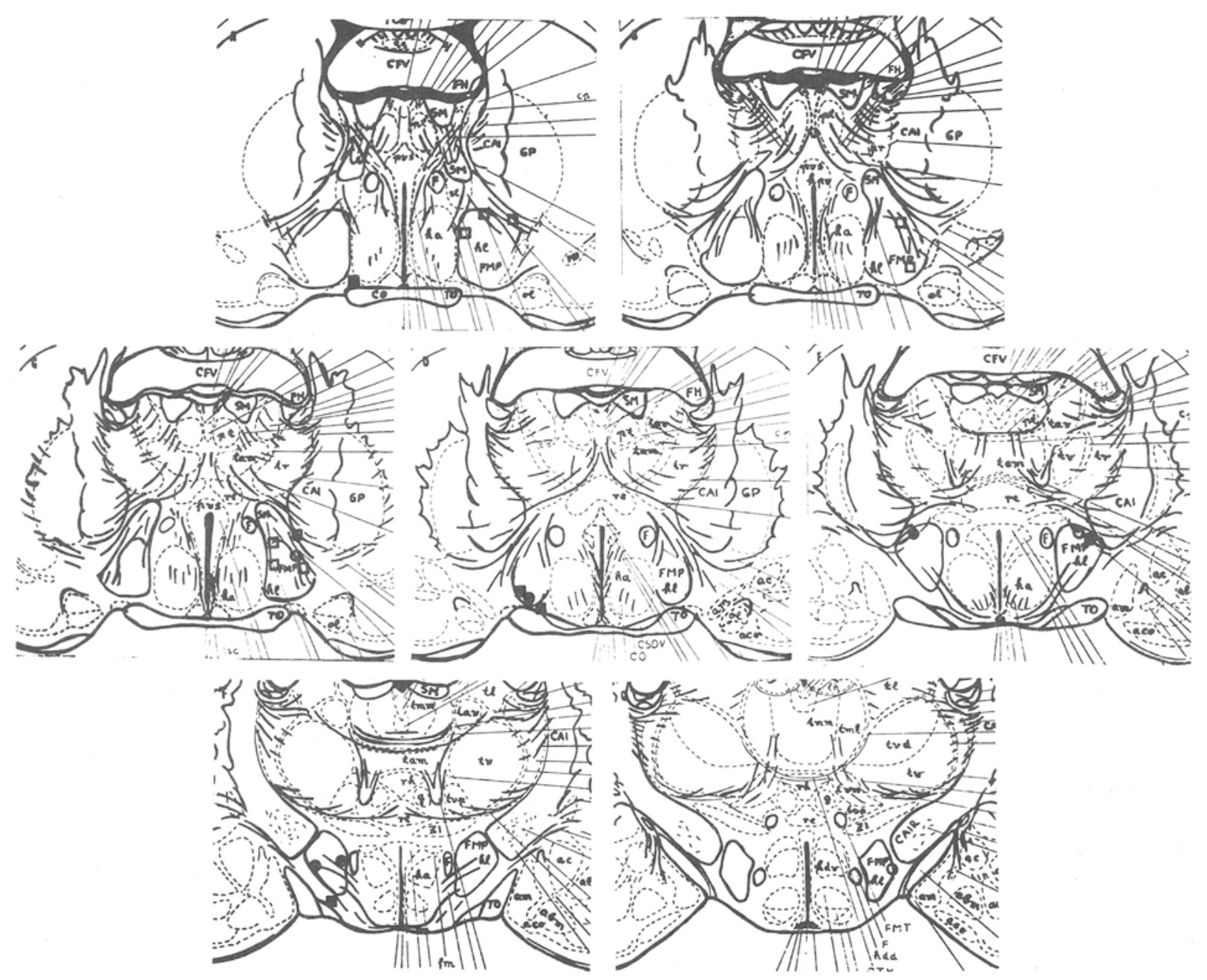

Figure 3. Electrode placements in Phase 2 for stimulated animals and implanted controls with MFB placements at the lateral hypothalamic level. Retention latencies are indicated as described under Figure 1. Stimulated animals appear on the left and implanted controls on the right.

capable of supporting that behavior (Routtenberg, 1973). It is reasonable to presume with regard to memory disruption that several fiber pathways within the MFB, orthodromically or antidromically activated, may be responsible for the deficits in performance observed during retention.

On the basis of three studies of brain stimulation disruption of retention using the present passive avoidance step-down retention paradigm, it may be possible to suggest such fiber pathways. First, Bresnahan and Routtenberg (1972) have shown that stimulation of the medial nucleus of the amygdala leads to memory disruption, and there are other reports of passive avoidance retention disruption following unilateral amygdala stimulation which also implicate the amygdala in memory processes (Gold, Edwards, \& McGaugh, 1975; Pellegrino, 1965). There are several pathways that connect the amygdala with the hypo- thalamus in general, and the medial forebrain bundle in particular. These connections are both afferent and efferent (Cowan, Raisman, \& Powell, 1965). Since the present study does show retention disruption following MFB stimulation during learning, it is possible that one or more of these amygdala pathways may be involved in the observed performance deficit. Secondly, Routtenberg and Holzman (1973) have shown that stimulation of the substantia nigra, pars compacta, leads to memory disruption. Since there are prior reports indicating an involvement of the caudate nucleus in memory, the nigrostriatal and striatonigral pathways can also be implicated in memory processes (Wyers, Peeke, Williston, \& Herz, 1968). Third, and finally, retention deficits following stimulation of medial frontal cortex have been reported by Santos-Anderson and Routtenberg (1976). The efferent fibers from the medial cortex also occupy 
a position in the lateral edge of the medial forebrain bundle (Leonard, 1969; Routtenberg, 1970). Thus, these three fiber pathways, originating from regions that have been implicated in memory disruption, are likely candidates for the disruptive effects of MFB stimulation.

Since 7 of the 19 MFB implanted controls showed a retention deficit in the second phase of the experiment, it may be that it is not the stimulation of these previously mentioned nigrostriatal and striatonigral fibers that result in retention disruption but rather the small lesions along this pathway caused by the implantation of the electrode. Although this issue is difficult to resolve, several points are relevant. First, considering all subjects, stimulation in the MFB at the lateral hypothalamic and lateral preoptic levels did result in a statistically significant retention deficit relative to implanted controls. Secondly, it is possible that brain stimulation and lesions are achieving the same effect, that is, disruption of MFB functions. If true, then the partial lesion caused by the implanted electrode and the brain stimulation could interact in their effects. It needs to be emphasized, however, that a statistically significant deficit in retention relative to implanted controls was demonstrated for MFB stimulated subjects in Phase 2. Thirdly, the failure to obtain a lesion effect due to electrode placement in Phase 1 suggests that the lesionproduced retention deficit may not be a robust effect. However, the placements of the electrodes in the implanted control animals in Phase 1 did not correspond exactly to the electrode placements in the stimulated animals. Thus, the effect of lesioning due to electrode implantation cannot be unequivocally resolved by the present data. It has been shown by Kent and Grossman (1973) that knife cuts through this area do result in passive avoidance learning deficits. Also unilateral electrolytic lesions along the lateral MFB result in passive avoidance retention disruption (Bresnahan, unpublished observations). It seems likely that brain stimulation of MFB causes disruption of performance both as a result of the electrode implant itself and as a result of the electrical stimulation of this region. The relative contribution of each factor has not yet been determined.

The present results support the view presented earlier by Bresnahan and Routtenberg (1972) that unilateral, low-level stimulation of restricted brain regions is an effective means by which anatomical localizaton of fiber systems related to retention performance can be achieved. In order to achieve such localization, we recognize that, using these milder procedures, retention disruption might not be complete. Presumably, more intense current levels and bilateral stimulation might produce larger deficits. This, however, would compromise the anatomical localization that might be obtained. As pointed out by Routtenberg (1973), no matter how small the electrode tip used or how mild the current level employed, localization cannot be made on the basis of electrode tip placement alone. Thus, other experimental anatomical techniques such as the Fink-Heimer method and fluorescence histochemistry may be profitably applied to the identification of the fiber pathways implicated in this study (Clavier \& Routtenberg, 1974; Routtenberg, 1970).

It should be noted that the paradigm used in the present study does not distinguish between various stages of information processing, storage of information, or retrieval processes, because stimulation is applied during the learning task while the animal is on the platform. However, the emphasis in this experiment is on the identification of particular pathways related to the ability of an animal to withhold a response and retention of that withheld response.

\section{REFERENCES}

Bresnahan, E., \& Routtenberg, A. Memory disruption by unilateral, low-level subseizure stimulation of the medial amygdaloid nucleus. Physiology \& Behavior, 1972, 9, 513-525.

Briese, E., \& OLDS, J. Reinforcing brain stimulation and memory in monkeys. Experimental Neurology, 1964, 10, 493-508.

Clavier, R. M., \& Routtenberg, A. Ascending monoamine containing fiber pathways related to intracranial self stimulation: Histochemical fluorescence study. Brain Research, 1974, 72, 25-40.

Cowan, W. M., Raisman, G., \& Powell, T. P. S. The connexions of the amygdala. Journal of Neurology, Neurosurgery and Psychiatry, 1965, 28, 137-151.

Gold, P. E., Edwards, R., \& McGaugh, J. L. Amnesia produced by unilateral subseizure stimulation of the amygdala in rats. Behavioral Biology, 1975, 15, 95-105.

Kent, E. W., \& Grossman, S. P. Elimination of learned behaviors after trans-section of fibers crossing the lateral border of the hypothalamus. Physiology \& Behavior, 1973, 10, 953-963.

Kesner, R. P., \& Wilburn, M. W. A review of electrical stimulation of the brain in context of learning and retention. Behavioral Biology, 1974, 10, 259-293.

Konig, J. F. R., \& KlipPel, R. A. The rat brain. Baltimore: Williams \& Wilkins, 1963.

LeOnard, C. M. The prefrontal cortex of the rat. I. Cortical projections of the mediodorsal nucleus. II. Efferent connections. Brain Research, 1969, 12, 321-343.

Moore, R. Y., Bhatnagar, R. K., \& Heller, A. Anatomical and chemical studies of a nigro-neostriatal projection in the cat. Brain Research, 1971, 30, 119-136.

Pellegrino, L. The effects of amygdaloid stimulation on passive avoidance. Psychonomic Science, 1965, 2, 189-190.

Olds, M. E., \& Olds, J. Emotional and associative mechanisms in rat brain. Journal of Comparative and Physiological Psychology, 1961, 54, 120-129.

RoutTenberg, A. Forebrain pathways of reward in Rattus norvegicus. Journal of Comparative and Physiological Psychology, 1970, 75, 269-276.

ROUTTENBERG, A. Intracranial self-stimulation pathways as substrate for stimulus-response integration. In J. Maser (Ed.), Efferent organization for integrative behavior. New York: Academic Press, 1973.

Routtenberg, A., \& Holzman, N. Memory disruption by electrical stimulation of substantia nigra, pars compacta. Science, 1973, 181, 83-86.

Santos-Ande rson, R., \& Routtenberg, A. Stimulation of rat medial or sulcal prefrontal cortex during passive avoidance 
learning differentially influences retention performance. Brain Research, 1976, 103, 243-259.

Valenstein, E. S., \& Myers, W. J. Rate independent test of reinforcing consequences of brain stimulation. Journal of Comparative and Physiological Psychology, 1964, 57, 52-60.

WEIL, A. A rapid method for staining myelin sheaths. Archives of Neurology and Psychiatry, 1928, 20, 392.

Wyers, E. J., Peeke, H. V. S., Williston, J. S., \& Herz, M. J. Retroactive impairment of passive avoidance learning by stimulation of the caudate nucleus. Experimental Neurology, $1968,22,350-366$.
NOTE

1. This study was begun while the first author was a Postdoctoral Research Fellow at Northwestern University and was completed while the first author was a Postdoctoral Research Fellow under the direction of Dr. David C. Wood at the University of Pittsburgh. The study is described in two separate phases, as experimental conditions were not identical in the two locations.

(Received for publication November 13, 1979; revision accepted January 9,1980 .)

\section{EDITOR'S NOTE}

In honor of the centennial year of psychology, we reprint below the final examination in graduate-level physiological psychology given by William James 100 years ago. It is somewhat sobering to note that several of these questions remain almost as intractable today. This examination was provided through the kind offices of Dr. D. B. Klein, Professor Emeritus, University of Southern California.

\section{FINAL EXAMINATION IN JAMES' GRADUATE COURSE IN PHYSIOLOGICAL PSYCHOLOGY (PHILOSOPHY 19), 1879-1880}

1. Meaning of "efferent" and "afferent" nerve processes?

2. What are the basal ganglia of the brain?

3. What is probably their function as contrasted with that of the hemispheres?

4. Can actions accompanied by intelligence be conceived under the form of reflex action?

5. What is the present state of the question of localization of functions in the cortex?

6. What were the most characteristic points in your instructor's sketch of space-perception?

7. What proof does there seem to be that the sense of motion is not a synthesis of positions in space occupied in successive moments of time?

8. Why does an ataxic patient walk better with his eyes open? To the disorder of what function do his symptoms essentially seem due?

9. What is the most plausible argument in favor of feelings of efferent innervation? Why is it nugatory?
10. What is muscular effort proper?

11. What is moral or volitional effort proper?

12. It is commonly said that in the phenomenon of effort and there alone, we have a direct transitive relation between the inner and the outer worlds, the outgoing force in the former recognizing as its antagonist an equivalent force in the latter, which opposes it. And this is said to be our only immediate perception of outward reality. Criticize this doctrine from the point of view of your instructor's opinions.

13. Would the untruth of the "conscious automaton" theory involve the truth of the free will theory?

14. Does the fact that red light and green light combine on the retina into a feeling of yellow prove that our consciousness of yellow is made up of unconscious feelings of red and green? If not, why not?

15. The most important points for and against in No. 14. 